\title{
Impacts of renewable energy in the current business model of Latin American utilities
}

\author{
F. E. Giraldo \\ Empresas Publicas de Medellin (EPM), Colombia
}

\begin{abstract}
In recent years, climate change has become a central issue worldwide. Therefore, this aspect has evidently influenced environmental and political decisions. As a result, renewable energy has emerged as an alternative to diminish the footprint caused to the environment. Consequently, several projects have been built in Europe to diversify the energy mix and reduce $\mathrm{CO}_{2}$ emissions. Regarding Latin America, the production of electricity has been based on hydropower generation from big-scale projects. This has led low-cost electricity to meet the demand. However, environmental and social issues have recently caused an increase in hydropower generation costs. Additionally, the growing maturity of renewable energy technologies has fostered a reduction in their production costs. Therefore, renewable energy in Latin America may be developed massively. This paper reports the current state of renewable energy in many Latin American countries. Besides, the main impacts that renewable energy may cause in utilities are described. These impacts include new competitors, increase of small-scale generation projects, decrease in risk assessment indicators, revenues based on network availability and, finally, changes in network topology. Hence, a redefinition of the business model of Latin American utilities is suggested which shall focus on adequate asset management programs and optimization of energy infrastructure. Furthermore, technical advice about energy-efficiency on the customers' side is a vital aspect that is likely to strengthen the relationship with utility-customers to guarantee utilities' sustainability. Regarding novel services to be provided, solar photovoltaic installations and electric vehicle charge have been identified as solutions that might be included into the utilities services portfolio due to their proximity to core business and market attractiveness.

Keywords: utilities, renewables, business model, Latin America, energy mix.
\end{abstract}




\section{Introduction}

Energy safety is a vital aspect for development across the world. In recent years, climate change has influenced environmental and political decisions. In addition, as part of the strategical aspects of different nations, several concerns have emerged about energy dependence. These issues can be analysed from the energy mix corresponding to each country. The dependence on different types of fuel may affect energy supply due to two reasons. Firstly, cost variability of the fuel due to macroeconomic aspects and, secondly, due to the availability of the fuel to supply the demand required. The previous affairs may considerably cause an increase in energy costs.

For the case of Latin America, electricity has a considerable share of energy mix. Additionally, electricity has been mostly based on hydropower big-scale projects which is result of the geographical conditions. As a result, electricity generation in many Latin-American countries has a low cost. However, aspects such as cost of land purchased, compensations to communities and armed conflict, have increasingly impacted big-scale hydropower projects in Latin America and, particularly, in Colombia. These previous aspects have caused an increase of electricity generation costs.

Therefore, renewable energy has been considered as an alternative to diversify the energy mix and to diminish the reliance on fossil fuels and big-scale hydropower projects. Nowadays, the use of renewables in Latin America has been gradually increasing as a result of their maturity and the gradual decrease in the electricity production costs. However, the development of renewable energy depends on the regulatory aspects that can be defined in order to foster its utilisation.

This paper will illustrate a general description about the current state of renewables in many countries of Latin America, the expected impact that renewables may cause to utilities and some actions that the utilities can develop to mitigate these impacts on their business model and their sustainability.

\section{Renewable energy in Latin America}

The state of renewable energy in Latin America is evidently influenced by technical and regulatory conditions in each country. Regarding technical issues, Latin America has geographic conditions that favour the development of projects in this arena.

Figure 1 illustrates the energy consumption for Latin America in 2013 compared to other regions of the world [1].

As can be seen from Figure 1, 2.72\% of the energy in Latin America is obtained from renewables. This value is quite similar to the ones for North America and Europe which are $2.35 \%$ and $3.95 \%$, respectively. Regarding hydroelectricity, $23.5 \%$ of the mix energy corresponded to Latin America whereas North America and Europe reached 5.6\% and 6.9\%, respectively. Despite the fact that hydropower has been considered as renewable energy, this 


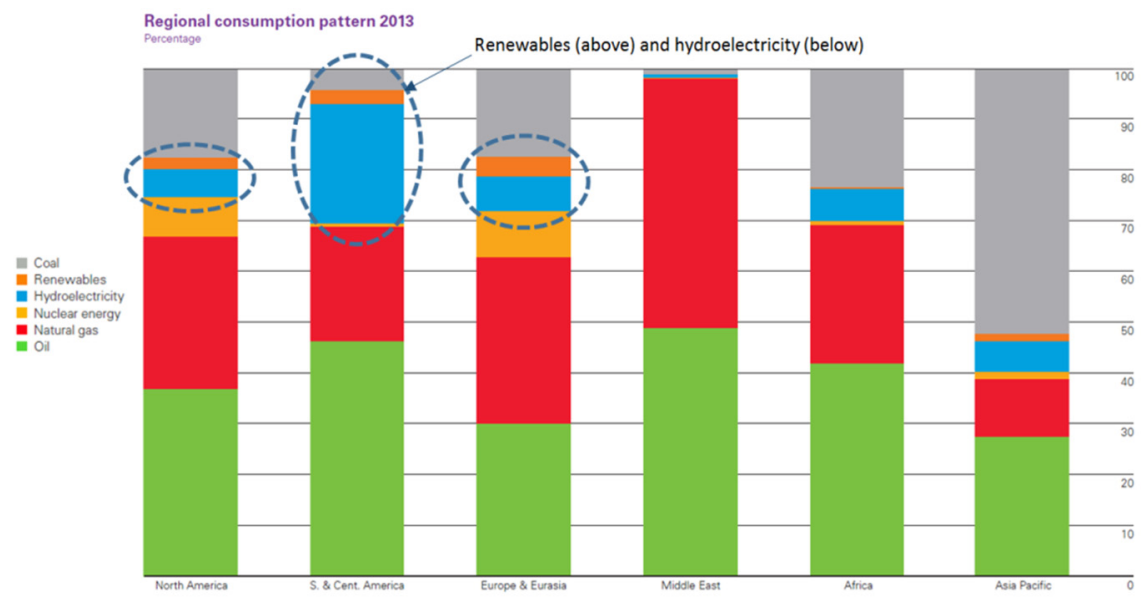

Figure 1: $\quad$ Energy mix pattern for regions across the world in 2013.

paper will focus in solar and wind power since these are the energy technologies that may potentially affect the current business model of utilities.

Figure 2 illustrates the resources in Latin America in terms of wind and solar $[2,3]$.

As shown in Figure 2, higher irradiance levels (over $6 \mathrm{kWh} / \mathrm{m}^{2} /$ day) are expected for Pacific coastal areas across Chile, Peru and Mexico. In relation to wind, higher wind speed values (over $5 \mathrm{~m} / \mathrm{s}$ ) are observed for Atlantic coastal areas across Argentina, Brazil, Venezuela and Mexico.

\subsection{Technical perspective}

Solar photovoltaic and wind power are the main energy technologies that have been developed in Latin America. Geothermal and biomass power have been applied to a few of projects whereas tidal energy has no considerable application.

Table 1 shows the contribution of renewables as part of the mix energy for some countries in Latin America [1].

Table 1: Renewables as part of mix energy in some countries.

\begin{tabular}{|c|c|}
\hline Brazil & $4.65 \%$ \\
\hline Chile & $4.05 \%$ \\
\hline Mexico & $1.33 \%$ \\
\hline Peru & $0.92 \%$ \\
\hline Colombia & $0.26 \%$ \\
\hline
\end{tabular}

As shown in Table 1, Brazil and Chile are the countries with higher implementation of renewables. Hydroelectricity is not considered for these values. 


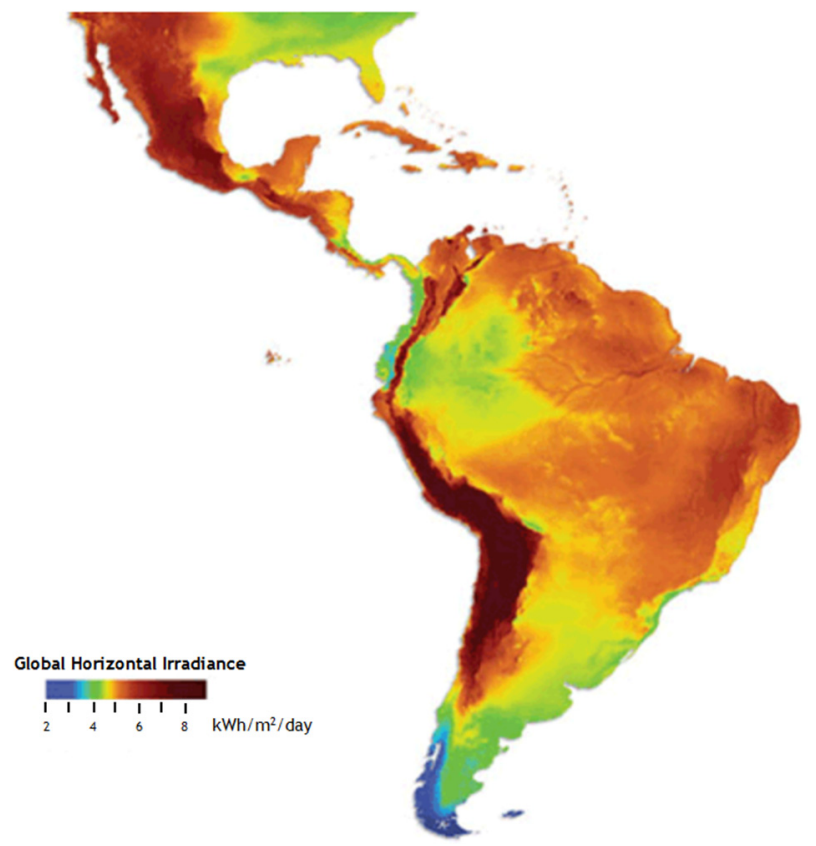

(a)

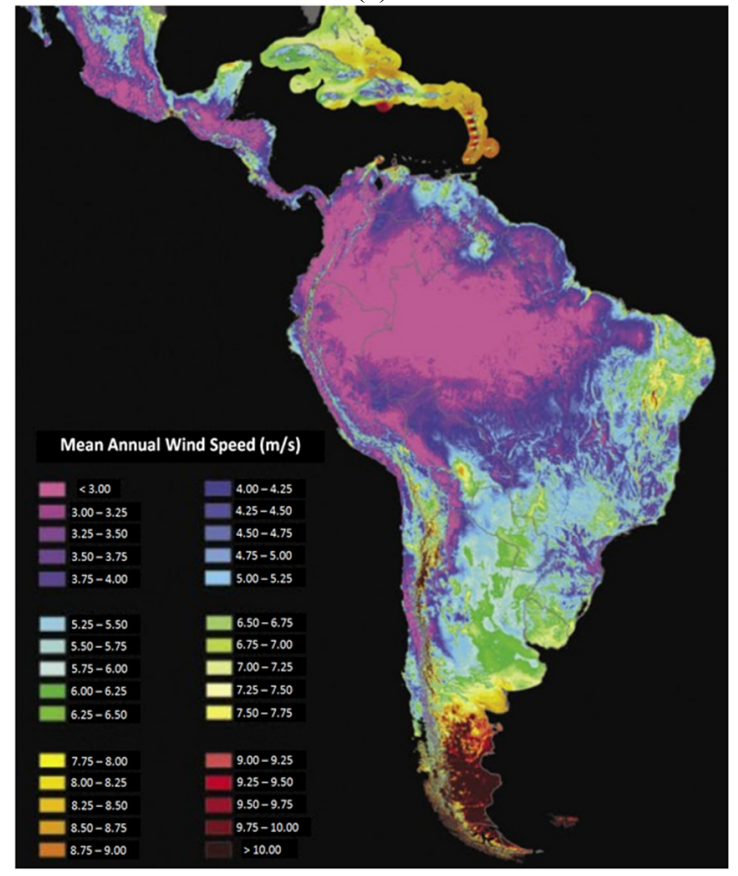

(b)

Figure 2: $\quad$ Solar (a) and wind (b) resources in Latin America. 


\subsection{Regulatory perspective}

Many countries have established regulations to meet international environmental policies in order to tackle the climate change.

\subsubsection{Brazil}

In 2002, the "Incentive Program Alternative Energy Sources (PROINFA)" was created to foster the development of new projects across the country [4]. The first phase of this program defined general policies for small hydropower plants, biomass and wind power. The second phase set a target for renewables to supply $10 \%$ of the country's annual power consumption within 20 years. Currently, auction systems were introduced due to the limitations of PROINFA.

\subsubsection{Chile}

In 2008, the Law 20257 "Non-Conventional Renewable Energy (NCRE) Law" was enacted to develop new energy sources and to allow clients to sell surplus regulated self-generation to power distribution companies [5]. In 2013, the Law $20 / 25$ was enacted with the purpose to led to the expansion of the energy matrix through non-conventional renewable sources. Additionally, a goal was established to achieve that $20 \%$ of marketed energy should come from nonconventional renewable energies by 2025 .

\subsubsection{Mexico}

In 2008, the Law on the Use of Renewable Energies and Financing of Energy Transition (LAERFTE) was published to define and regulate the use of renewables. The 2011 reform established maximum targets of fossil generation for $2024(65 \%), 2035(60 \%)$ and $2050(50 \%)$ [6].

\subsubsection{Colombia}

The Law 1715 of 2014 defined some aspects in order to encourage the use of renewable energy as well as to create a landscape that promotes private investment in this area [7]. Some aspects are the following:

- Promotion of self-generation and distributed generation (small and large).

- Establishment of Non-Conventional Energy Fund and Efficient Energy Management (FENOGE): Financing small-scale self-generation and energy efficiency.

- Definition of incentives as a deduction from income, excluding VAT, tariff exemptions, accelerated depreciation of assets.

Additionally, the current regulatory framework will involve a major interest from industry toward implementing energy efficiency programs (ISO 50001).

\section{Expected impact on utilities}

The gradual incursion of renewables in the energy mix has impacted all actors involved in this business. This paper focuses on the impacts on the "utilities", mainly in economic, technical and strategic aspects, to the point, involve a change in the concept of "utility" of the 21 st century. 


\subsection{Economic impacts}

\subsubsection{Reduction of income due to fewer energy demand and new competitors}

The implementation of renewable energy policies aims to reduce the cost of electricity. Also, if there is a scheme that allows the sale of surplus to the network operator, the business model becomes more feasible. This shortens the price gap between the cost of conventional and non-conventional energy. Additionally, new competitors will appear and sell energy solutions directly to customers. Regarding this issue, RWE CEO claims that the movement from large conventional power plants to decentralized plants is a change that is affecting the economic viability of plants of RWE. In Germany, this aspect has been also studied by Lueneburg University. To this regard, it has been said that $22 \%$ of electricity came from solar energy (2012) and that the big four "utilities" were not part of this sector. Additionally, this university has argued that the utilities produce electricity and there are now new technologies to produce electricity, but the utilities are not being present. Therefore, these companies are missing a huge market opportunity [8].

\subsubsection{Injury in the risk rating (Fitch rating)}

Some years ago, the utilities were known for their low risk investments where the probability of return was very high and the average risk ratings were mainly A category. Figure 3 shows the fitch ratings for utilities in the United States (US) between 1970 and 2010 [9].

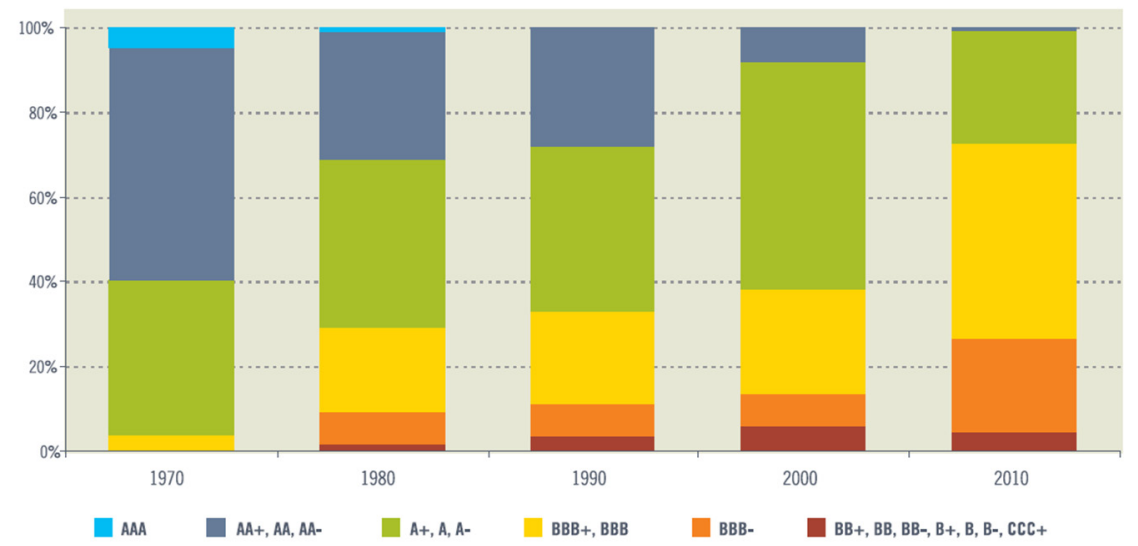

Figure 3: Fitch ratings between 1970 and 2010 for utilities in the US.

As can be seen Figure 3, there is a continuous decrease in the category of risk rating for the period analyzed. Besides, the current average rating for utilities is BBB category. This indicates that the business model for utilities is gradually becoming more risky. 


\subsection{Technical impacts}

\subsubsection{Increased generation "small scale" and change the configuration of the network infrastructure (vertical to horizontal)}

Conventionally, generation centers are located far away from load centers in cities. However, the new regulation will undoubtedly promote the commissioning of an increasing number of "small scale" projects. Hence, aspects such as energy self-sufficiency and sale of surpluses will have a substantial interest for customers. This aspect will cause a change of the topology of power grids. Therefore, the generation and load nodes will be connected at the same point. According to International Energy Agency (IEA), utilities may become "insurance companies" that will supply power when the primary resource is not needed to generate [10].

\subsubsection{Interface between customer power grid and power grid utilities}

The expected change in the topology of the networks will add higher complexity to control the power flow. Therefore, technical clarity is required as well as the definition of the optimum devices which will be required for control, protection and supply measurement. In particular, the bidirectional meters will be essential to quantify the power flowing through the system. Regarding protection, it is expected that adequate protection coordination will involve the use of smarter devices which should adequately infer the bidirectional power flow.

\section{Actions to mitigate impacts}

In order to face the "new competition" between utilities and renewables, some utilities have led the definition of strategies to ensure their sustainability in the energy market. Both an European company (GDF Suez) and an American company (Duke Energy) will be taken as references.

\subsection{GDF Suez}

This company realised that a decrease in the revenues had been obtained as micro-generation increased. This was due to the fact that some companies, which are not utilities, created business models to offer energy services for customers. Hence, this company redefined its business model based on four (4) new business lines [10]:

1. Search for growth in emerging markets where centralized generation model still works.

2. Set up an energy efficiency program specifically addressed to large energy customers.

3. Develop a business model for renewable energies considering that may be more successful in some countries than in others.

4. Allow installed capacity in standby (as backup of a self-generation plant) to receive payment due to availability.

GDF Suez Chairman and CEO has claimed that the new philosophy is, not only to adopt energy efficiency and renewable energy, but also to advise customers. 


\subsection{Duke energy}

This company began to lose part of its energy market since the introduction of renewable energy in the United States. Furthermore, the price of electricity began to increase in such a way that the costs of electricity obtained from conventional plants equaled the cost of electricity obtained from photovoltaic panels. This equivalence of costs occurred in $16 \%$ of the company market. For these reasons, an imminent change in the business model was immediately required [10].

To tackle these issues, the company initiated a program to manage and optimise both the existing assets and the reengineering designs. Additionally, the company defined a new policy to provide services for customers' energy infrastructure. The main purpose was to strength the relationship with customers and provide efficient energy solutions.

According to Jim Rogers, Duke Energy Chairman and CEO, the business in the 21 st century is to be a power optimiser, not only within the network but inside every home and every business.

\subsection{Proposed strategies}

Some consulting firms (Navigant, Bain \& Company and Strategy) have raised recommendations to be considered in the future business model of the utilities [11]. Some forecasts and recommendations identified are:

- The network of utilities will become the main supply backup. The utilities will earn more for availability than consumption.

- Consulting, supply, installation and maintenance of power generation system for the client. This analysis includes the study of project feasibility study of renewable resource, cost and time of return on investment.

- The utilities should create policies and strategies to reduce the impact of renewable energy development, and build business models for new services. The new strategy must take your current business to its full potential and raise investment in similar business with a replicable model.

- The utilities could sell smaller-scale energy solutions (solar panels, waste treatment systems, micro-turbines for buildings, etc), providing funding and network connection.

- $\quad$ Evaluate the option of offering energy efficiency service and business model known as "Energy Performance Contract". This is the type of agreements made by the Energy Service Companies (ESCOs) and other companies to transform their energy cost overruns on investment in energy efficiency assets.

- Do not continue with inadequate infrastructure oversizing. This aspect requires re-engineering criteria.

Figure 4 illustrates the comparison of business models for the utilities of the 20 th and 21 st centuries. This comparison was defined by the consulting firm Navigant [11]. 


\section{0th Century \\ 21st Century \\ Business Model \\ Business Model \\ - Simple, based on steadily increasing electricity sales typically from an expanding asset base of centralized generation and traditional delivery infrastructure \\ - Complex, integrated energy services serving diverse and evolving customer needs with an information-enabled infrastructure \\ Sources of Revenue \\ - Power plant capital expenditures, primarily for coal, nuclear, natural gas plants \\ - Transmission capital expenditures \\ - Sales of generated and procured electricity \\ - Modest energy efficiency programs in some states \\ Sources of Revenue \\ - Power plant capital expenditures, primarily for natural gas and large scale renewables plants, upgrades to fleet, also some coal w/CCS and nuclear \\ - Transmission capital expenditures \\ - Recovery of fixed and variable costs for electricity delivery under a revenue decoupling approach \\ - Aggressive energy efficiency programs in most states with financial incentives for performance \\ - Effectively deployed Smart Grid technology and services, including smart meters, energy storage, vehicle charging, etc. \\ - Utility-owned distributed renewables}

Figure 4: Comparison between utilities business model for the 20th and 21st century.

It is noted that new alternatives should be analyzed by utilities. The decision to adopt any of these services depends on two aspects: 1) the degree of interest from customers and 2) the degree of alignment between new services and the current core business of the utilities. Therefore, Figure 5 illustrates the potential services to be provided [12].

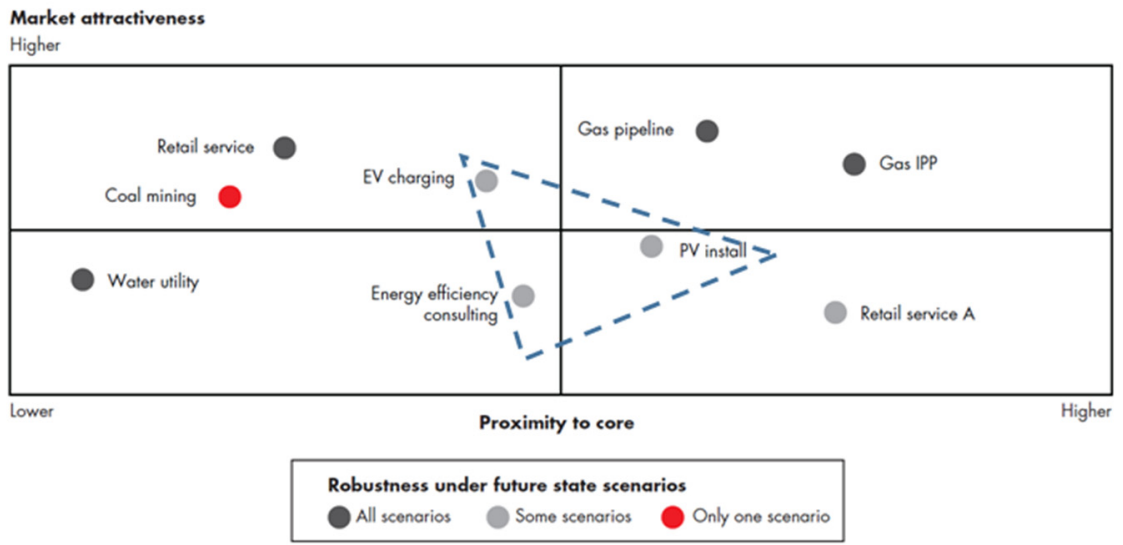

Figure 5: Analysis of options for business model for utilities of the 21st century (according to proximity to core and market attractiveness). 
From Figure 5, three potential services may be provided: 1) Load of electric vehicles, 2) Consulting in energy efficiency and 3) Installation of solar panels, thus:

- The business of electric vehicle charging has greater interest from the market, followed by the installation of solar panels and eventually consulting in energy efficiency.

- The business of installing solar panels has greater similarity to the core business of the current utilities, followed by energy efficiency consulting and finally, charging of electric vehicles.

- For these businesses, a study by the consulting firm Navigant states that utilities should also consider possibility of expanding its portfolio, including the business of supplying charging for electric vehicles and, in general, electrification of transportation systems.

\section{Conclusion}

The utilities of the 21 st century must redefine their strategy because the regulatory framework in many countries, aims to foster the entry of renewable energy in the energy mix. To achieve this, some utilities have defined a new business model which have focused on the optimization and management of existing assets, as well as in strengthening the relationship with customers through technical assistance and implementation of energy efficiency solutions. In addition, the utilities are valuing the inclusion of services such as installing solar panels and electric vehicle charging. The first service is motivated by a defense strategy market, while the second, as an opportunity to take the market from providers of fossil fuels. It is recommended to identify those utilities that are leading the definition and implementation of a new business model. By defining a novel business model for utilities, Latin America will promote an adequate framework to face the forthcoming challenges in the energetic arena.

\section{References}

[1] BP Statistical Review of World Energy; British Petroleum, Online. www.bp.com/content/dam/bp/pdf/Energy-economics/statisticalreview-2014/BP-statistical-review-of-world-energy-2014-full-report.pdf

[2] Why Solar; Ecosolar, Online. www.ecosolar.com/page/en-why-solar

[3] Wind data and resource maps online for Latin America; Wind Power Engineering and Development, Online. www.windpowerengineering.com/ construction/projects/site-assessments/wind-data-resource-maps-onlinelatin-america/

[4] Brazil Market Overview; International Renewable Energy Agency (IRENA), Online. www.irena.org/DocumentDownloads/Publications/ GWEC_Brazil.pdf

[5] Non-conventional renewable energy law (Law 20.257); International Energy Agency (IEA), Online. www.iea.org/policiesandmeasures /pams/chile/name-24577-en.php. 
[6] Law for the Development of Renewable Energy and Energy Transition Financing (LAFAERTE); International Energy Agency (IEA), Online. www.iea.org/policiesandmeasures/pams/mexico/name-24706-en.php

[7] Colombia Enacts Key Law Promoting Renewables; Cleantechies, Online. cleantechies.com/2014/09/03/colombia-enacts-key-law-promotingrenewables/

[8] CEO of German Utility RWE Says It Should Have Invested in Renewable Energy Sooner; Renewable Energy World, Online. www.renewableenergyworld.com/rea/news/article/2014/04/ceo-of-german -utility-rwe-says-it-should-have-invested-in-renewable-energy-sooner

[9] Ceres, Practicing Risk-Aware Electricity Regulation, Ceres: Boston, p. 18, 2012.

[10] Analysis: Renewables turn utilities into dinosaurs of the energy world; Reuters, Online. www.reuters.com/article/2013/03/08/us-utilities-threatidUSBRE92709E20130308

[11] The $21^{\text {st }}$ century electric utility; Ceres, Online. http://www.ceres.org/resources/reports/the-21st-century-electric-utility positioning-for-a-low-carbon-future-1

[12] Utilities: the road ahead; Bain and Company, Online. http://www.bain.com/Images/BAIN_BRIEF_Utilities_The_road_ ahead.pdf 